\title{
Parientes, criados y allegados: los vínculos personales en el mundo virreinal peruano
}

\author{
Z M A R A R I TA S UÁREZ, EDITORA \\ Lima: Pontificia Universidad Católica del Perú, Instituto Riva-Agüero \\ 2017 |ISBN 9789972832901 | 209 pp.
}

DOI: https://doi.org/I0.22380/20274688.2056

$\mathrm{D}$ urante la Colonia, los criados eran imprescindibles en la vida social de los notables asentados en los centros urbanos, como también de los encomenderos, los funcionarios reales y los oficiales de las milicias. Por ejemplo, el cura Diego de Gasco recordaba que por real provisión de 1594 se tenía prohibido que a "los encomenderos, sus mugeres, hijos y criados no pudiessen estar, entrar, vivir, ni recidir en los repartimientos de indios de sus encomiendas". Tampoco podían ser doctrineros "los hijos, sobrinos ni parientes de los encomenderos por el perjuicio que se les sigue a los indios”. Es decir, desde temprano, en la sociedad colonial se reconocía la existencia de redes clientelares por medio de los criados que formaban parte de la familia.

En el siglo XviıI, con motivo de la llegada del virrey don Manuel de Guirior a Cartagena, este les concedió a los mercaderes agrupados en la Compañía de Mercaderes de las Milicias Urbanas de Cartagena el derecho de que el gobernador, acompańado de dos miembros de la Compañía, conociera sus causas mercantiles y criminales. Sin embargo, el auditor y los alcaldes observaron el perjuicio que esta decisión causaba a la jurisdicción ordinaria, puesto que "el Cuerpo de mercaderes se compone de un número indefinido de individuos entre los cuales entran sus mancevos y criados" (AGN, sC, FMM, t. 68, f. 88 v.); es decir, los criados formaban parte de los vínculos familiares de los comerciantes cartageneros. 
El virrey era considerado el primer criado del rey, al igual que algunos funcionarios, como Joseph de Palacios quien escribió al virrey el II de noviembre de 1777 que "deceando ser conosido hasta en el traje por criado del Rey N[uest] ro Señor" (AGN, SC, FMM, t. IO9, f. 53I r. Énfasis con cursiva añadido), solicitaba el uso del "uniforme de guerra", pues tenía que pasar revista a los soldados que se encontraban de reclutas.

Era común resaltar los vínculos familiares, existía el afán de declararse parte de la familia de un virrey o pariente de un encomendero. El i9 de octubre de 176I, Juan Antonio de Iriarte y Marzan llegó al puerto de Cartagena y de inmediato manifestó "ser aijado del Sr Marqués de Espínola y recuerda la recomendación q[u]e éste Caballero hizo a S.E. en Madrid" (AGN, SC, FMM, t. 72 , f. 133 r.).

La historia social de los criados está vinculada al tema de la gratitud, la justicia distributiva, los vínculos familiares y las "dádivas, dones y dineros" en la sociedad colonial. En tal sentido, resulta novedosa y muy sugestiva la obra que edita Margarita Suárez, Parientes, criados y allegados: los vinculos personales en el mundo virreinal peruano, en la cual se analiza que los "los vínculos familiares, de amistad, clientelismo y paisanaje eran medulares para la acción política".

La obra se compone de dos partes, la primera se ocupa del "Poder político, clientelismo y patronazgo", con el artículo de Alejandro Cañeque cuyo sugestivo título es "Los virreinatos de América en los siglos XVI y XVII: un gobierno de parientes y amigos", en el que se analiza cómo en la sociedad virreinal del Perú dominaba la cultura del favor. El virrey, considerado la viva imagen del rey, y un "criado asalariado" de este, concedía todo tipo de favores, mercedes y gracias a nombre de su monarca. Según Cañeque, ello no debe verse como corrupción, como se considera hoy en día, sino como una forma de darle cohesión a la monarquía hispánica y crear fuertes lazos de lealtad con el monarca distante. Empero, escribe Cañeque, los virreyes quienes se rodeaban con un amplio séquito de parientes y criados, la familia, en sus destinos, los virreinatos, también entregaban oficios o mercedes a estos.

Otro aspecto interesante del artículo se refiere, en primer lugar, al análisis del concepto aristotélico de amistad para entender las relaciones clientelares que se tejían en las sociedades virreinales y, en segundo lugar, comprender la cultura política monárquica colonial dentro de las leyes del agradecimiento, contexto en el que la ingratitud representaba lo peor. Otra investigación interesante en la línea del estudio de la corte virreinal, aunque no forma parte del libro, es “El poder transfigurado. El virrey como la 'viva imagen del rey' en la Nueva 
España de los siglos XVI y xviı, en la que se muestra cómo "la conservación de las monarquías dependía de la autoridad y estimación de sus gobernantes".

En el artículo "De parientes, criados y gracias. Cultura del don y poder en el México colonial (siglos XVI-Xvir)", Cañeque profundiza acerca de la cultura del don y la justicia distributiva y la gratitud en el mundo colonial.

El segundo artículo, de L. Miguel Costa Vigo, "Por no yr tan solo. Redes clientelares y dinámicas de poder en el virreinato del Perú: el caso del gobierno del virrey conde del Villar, 1585-1590”, se estudia una crisis política que estalló en 1588 en el virreinato del Perú, con el fin de examinar el funcionamiento del sistema político colonial. Según Costa Vigo, contrariamente a lo que considera la literatura, "las redes clientelares otorgaron al rey un enorme poder en tanto autoridad y árbitro en las dinámicas de poder en su territorio”. Para demostrar su hipótesis, analiza el caso del virrey Conde del Villar, quien llegó a Lima con una comitiva de 62 personas entre parientes y criados, y veintinueve personas entre familiares y amigos, a quienes atendió con mercedes. Otra lista de favoritos de las cercanías del virrey para hacer un buen gobierno estaba formada por oidores y magistrados de la Real Audiencia de Lima y Charcas, quienes completaban su red clientelar. No obstante, hubo enfrentamiento entre el virrey y el inquisidor Antonio Gutiérrez de Ulloa.

El artículo de la historiadora Margarita Suárez, titulado "Beneméritos, criados y allegados durante el gobierno del virrey Conde de Castellar: ¡el fin de la administración de los parientes?”, aborda el caso de corrupción (diríamos hoy) del virrey del Perú Conde Castellar por medio de sus criados. La investigación se inscribe en los estudios de la corte del rico virreinato del Perú de los tiempos de los Austrias, la autora sostiene que "la corte del virrey se convirtió en el espacio de negociación por excelencia: allí se rendía pleitesía a la autoridad, se desplegaban rituales destinados a legitimar el poder monárquico [...]", "era la central política, el meollo del patronazgo del territorio"; es decir, el virrey debía repartir, negociar los cargos entre los beneméritos, pero no siempre fue así, como escribe Margarita Suárez. Justamente, el artículo analiza "el manejo del reparto de oficios” del virrey Conde de Castellar quien había llegado a Lima en 1674 acompañado de sus 69 criados, nada en comparación con los 174 que acompañaron al virrey Príncipe de Esquilache.

El virrey Conde de Castellar otorgó corregimientos a veintiséis criados y sus allegados en la Real Audiencia, aunque esta práctica ya venía desde antes cuando la misma Audiencia repartió cargos entre amigos y parientes de los oidores. En el reparto de mercedes que benefició al conde de Medellín, el virrey 
dijo que había cobrado los 2500 pesos que antes cobraban los antecesores por cada una de las gracias.

Los nombramientos generaron muchas quejas, puesto que se habían presentado 350 pretendientes a los 46 puestos que se repartieron, sin recibir un peso de los 6000 . En una carta anónima dirigida al Consejo de Indias se denunciaron las prácticas del virrey, que violaban los principios de justicia distributiva, como aquella inspirada por un asesor "loco" de nombrar a diecisiete criados en importantes cargos. Según los beneméritos, "el mejor de los criados tiene por blasón haberle servido de capigorrón en Salamanca cuando era pobre monigote colegial, dejando a los hombres hon rados y beneméritos que hay [...]". En realidad, el virrey Conde de Castellar se había ganado el odio no solo de los beneméritos, sino de los oficiales reales de Lima y de las provincias, quienes habían sido presionados a dar cuentas claras so pena de morir a garrotes, como les sucediera a los funcionarios de las cajas de La Paz, de acuerdo con información de Margarita Suárez. Además, el virrey había abusado de los ricos comerciantes agrupados en el Consulado de Lima.

Otras denuncias terminarían de hundir ante la Corona al odiado virrey, como, por ejemplo, haber monopolizado el comercio de harinas del Callao, solicitar dinero para sus negocios y haber puesto en cuarenta cargos a "criados de su casa”. Según Margarita Suárez, el virrey había roto el consenso político en la sociedad virreinal, lo cual le costó su destitución el 7 de julio de i678. No obstante, había aumentado las rentas reales, como afirma la autora, estudiosa del siglo Xvir, en un artículo titulado "Política imperial, presión fiscal y crisis política en el virreinato del Perú durante el gobierno del virrey conde de Castellar, I674-1678". Vale la pena mencionar en este sentido un artículo de Gleydi Sullón Barreto, titulado "Los criados portugueses del príncipe de Esquilche, virrey del Perú, I6I5-I62I”.

En el último artículo de la primera parte de esta obra, de título "La nueva ortodoxia americana: tensiones políticas entre criollos y el poder virreinal. El caso de los condes de Lemos y de la Granja”, Elio Vélez analiza el enfrentamiento entre el virrey conde de Lemos y el corregidor Luis Antonio de Oviedo, conde de la Granja.

La segunda parte de la obra, cuyo título es "La fuerza de los vínculos", comprende varios artículos acerca de la historia de las relacionales personales, como, por ejemplo, el de Arrigo Amadori, titulado "Lazos personales, gestión política y articulación del espacio en el Río de la Plata a inicios del siglo Xviı", o el de Augusto Espinoza, "Amistades terrenales: el claustro femenino como espacio de articulación 
social durante el siglo Xvir", que estudia cómo en el siglo XVII los conventos de Lima cultivaron la amistad de ricos comerciantes y por ende sus favores. Tener "lazos activos de intercambio de bienes o de influencia", como hijas abadesas en los conventos, aseguraba acceder a los créditos. El artículo de Cristina Mazzeo, "Redes familiares y espacios mercantiles: el caso de los Ixcue, siglo xvin", estudia el caso del comerciante Francisco Ixcue, cuyas conexiones con Lima, Santiago y Buenos Aires constituían "una red mercantil que traspasa de lo puramente local", gracias a sus redes familiares.

Por último, el artículo de Dionisio de Haro Romero, "Redes y actores de un sueño fallido: el Banco Auxiliar de Papel Moneda", analiza la primera experiencia peruana de emisión de papel moneda. Según el autor, el banco "vino a representar un intento por revivir los tradicionales vínculos entre el poder virreinal y el Tribunal del Consulado". Sin embargo, no se encuentra una relación entre la institución bancaria y los vínculos interpersonales, como en los otros trabajos.

Esta obra se encuentra llena de sugerencias investigativas acerca de la historia social de unos personajes grises, como lo fueron los humildes criados que la historiografía ha despreciado. Además, sugiere un tema que aún no ha sido abordado en la historiografía colombiana: las redes, los vínculos personales y también la historia de la "corrupción" en el mundo colonial.

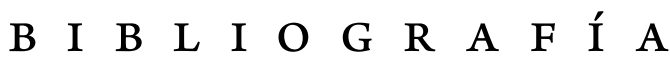

\section{Archivo General de la Nación, Colombia (AGN).}

Sección Colonia (sc)

Fondo Milicias y Marina (FMM)

Tomo 72 , f. 133 r.

Tomo 68, f. 088 v.

Tomo 109, f. 531 r. 